\title{
Deficiency of Src family kinases compromises the repopulating ability of hematopoietic stem cells
}

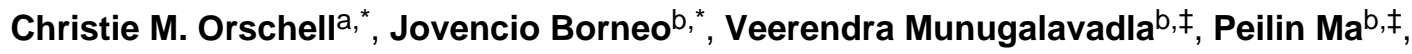 \\ Emily Sims $^{b}$, Baskar Ramdas ${ }^{b}$, Mervin C. Yoder ${ }^{b, c}$, and Reuben Kapur ${ }^{b, c, d}$ \\ aDepartment of Medicine, Herman B Wells Center for Pediatric Research, Indiana University \\ School of Medicine, Indianapolis, Ind., USA \\ ${ }^{b}$ Department of Pediatrics, Herman B Wells Center for Pediatric Research, Indiana University \\ School of Medicine, Indianapolis, Ind., USA \\ cMolecular Biology and Biochemistry, Herman B Wells Center for Pediatric Research, Indiana \\ University School of Medicine, Indianapolis, Ind., USA \\ dMedical andMolecular Genetics, Herman B Wells Center for Pediatric Research, Indiana \\ University School of Medicine, Indianapolis, Ind., USA
}

\section{Abstract}

Objective-Src family kinases (SFK) have been implicated in regulating growth factor and integrin-induced proliferation, migration, and gene expression in multiple cell types. However, little is known about the role of these kinases in the growth, homing, and engraftment potential of hematopoietic stem and progenitor cells.

Results-Here we show that loss of hematopoietic-specific SFKs Hck, Fgr, and Lyn results in increased number of Sca- $1^{+} \mathrm{Lin}^{-}$cells in the bone marrow, which respond differentially to cytokine-induced growth in vitro and manifest a significant defect in the long-term repopulating potential in vivo. Interestingly, a significant increase in expression of adhesion molecules, known to coincide with the homing potential of wild-type bone marrow cells is also observed on the surface of $\mathrm{SFK}^{-/}$cells, although, this increase did not affect the homing potential of more primitive $\mathrm{Lin}^{-} \mathrm{Sca}-1^{+} \mathrm{SFK}^{-/}$cells. The stem cell-repopulating defect observed in mice transplanted with $\mathrm{SFK}^{-/-}$bone marrow cells is due to the loss of Lyn Src kinase, because deficiency of Lyn, but not Hck or Fgr, recapitulated the long-term stem cell defect observed in mice transplanted with $\mathrm{SFK}^{-/-}$bone marrow cells.

Conclusions-Taken together, our results demonstrate an essential role for Lyn kinase in positively regulating the long-term and multilineage engraftment of stem cells, which is distinct from its role in mature B cells and myeloid cells.

(C) 2008 ISEH - Society for Hematology and Stem Cells. Published by Elsevier Inc.

Offprint requests to: Reuben Kapur, Ph.D., Herman B Wells Center for Pediatric Research, Indiana University School of Medicine, Cancer Research Institute, 1044 W. Walnut Street, Room 425, Indianapolis, IN 46202; rkapur@iupui.edu.

*Drs. Orschell and Borneo contributed equally to this work and should be considered co-first authors.

†Drs. Munugalvadla and Ma contributed equally to this work and should be considered co-second authors. 
Engraftment and reconstitution of normal hematopoiesis following transplantation of hematopoietic stem/progenitor (HSC/P) cells is the product of several important parameters, including the ability of hematopoietic stem cells (HSC) to home to, anchor within, and survive in specialized bone marrow (BM) niches, followed by timely proliferation and selfrenewal of stem cells for life-long hematopoiesis. While investigators have sought to understand the mechanisms behind each individual step, engraftment remains largely undefined.

Besides homing and anchoring of HSC/P cells following transplantation, signals emanating from cytokine receptors also play a prominent role in regulating HSC/P cell growth and survival. In general, both positive and negative signals induced in response to cytokine stimulation contribute to this process. Deregulated signaling downstream from cytokine receptors can alter the growth and differentiation of these cells and, in some cases, contribute to leukemogenesis. Examples of molecules that are activated in response to hematopoietic growth factors include, but are not limited to, nonreceptor tyrosine kinases, such as Src family kinases (SFKs). SFKs function in signal transduction from growth factor receptors for granulocyte macrophage colony-stimulating factor (GM-CSF), interleukin (IL)-3, IL-5, stem cell factor (SCF), erythropoietin, M-CSF, G-CSF, thrombopoietin, and Flt3 [1-16]. Although diverse cytokine receptors activate SFKs in response to ligand binding, most of the data thus far has been derived by studying cell-line models using dominant negative and activating approaches. Thus, the physiologic relevance of SFK activation in primary HSC/Ps is poorly understood.

Among the known Src family kinases, Lyn, Hck, and Fgr are expressed exclusively in the hematopoietic compartment [17]. Unique functions for SFKs have been identified by conducting experiments in mice lacking the expression of each one of these family members [17]. However, the phenotypes of these mice are often subtle due to functional redundancy between individual family members. For example, it is still not fully clear the extent to which Hck regulates myeloid cell functions, as the phenotype of $\mathrm{Hck}^{-/}$mice was limited to a mild defect in $\mathrm{Fc}$ receptor-independent phagocytic activity of macrophages. Mutant mice of Src kinases lacking more than one family member have suggested a broader as well as a redundant role for Hck and Fgr family members in regulating myeloid cell functions [17]. In contrast, deficiency of Lyn alone affects both positive and negative aspects of receptor signaling in myeloid and lymphoid cells [18]. $\mathrm{Lyn}^{-/-}$mice are hyperresponsive to myeloid growth factors and develop a myeloproliferative disorder due, in part, to loss of negative regulation through SHP-1 and SHIP phosphatases [19]. The importance of regulating Lyn activation is further demonstrated by additional pathological changes that occur in Lyndeficient mice, including lethal antibody-mediated autoimmune disease [20-23]. Lyndeficient mice succumb to autoimmune disease, and B cells from Lyn-deficient mice demonstrate hypersensitivity to B-cell receptor (BCR) stimulation. In the B-cell compartment, in addition to positively contributing to BCR-induced ty-rosine phosphorylation, Lyn also plays an essential nonredundant role in phosphorylating specific tyrosine residues present in the immunoreceptor tyrosine-based inhibitory motifs in the cytoplasmic domains of inhibitory receptors, such as CD22 [24,25] and Fc $\gamma$ RIIB [22,26]. 
Based on these studies, it is clear that Lyn plays an essential role in regulating signals via several cytokine and antigen receptors in mature myeloid progenitors as well as in B cells; it is, however, not known how deficiency of Lyn impacts long-term repopulating ability of stem cells in a myeloablated host. Furthermore, it is not known how well the stem/ progenitors cells from Lyn-deficient mice compete with normal wild-type (WT) BM cells in a competitive repopulation assay and whether there is redundancy and/or specificity between the functions of other hematopoietic-specific Src family kinases, such as Hck and Fgr, in regard to regulating long-term repopulating ability of stem cells. Given the involvement of Src kinases in regulating the trafficking and growth of nonhematopoietic cells as well as of more mature hematopoietic cells, including macrophages, neutrophils, and B cells, we initiated the present study to determine the involvement of hematopoietic-specific Src kinases Hck, Fgr, and Lyn in homing and long-term engraftment of BM cells following myeloablative transplantation. Our results show that loss of hematopoietic-specific SFKs Hck, Fgr, and Lyn results in increased number of Sca- $1^{+} \mathrm{Lin}^{-}$cells in the BM, which respond differently to different cytokine stimuli in vitro and show a significant defect in the long-term repopulating potential in vivo. Interestingly, $\mathrm{BM}$ cells from $\mathrm{SFK}^{-1-}$ mice show a significant increase in expression of adhesion molecules, known to coincide with the homing potential of WT BM cells, however, this increase does not affect the homing potential of $\mathrm{SFK}^{-/-} \mathrm{Lin}^{-} \mathrm{Sca}-1^{+}$cells. The stem cell-repopulating defect observed in mice transplanted with $\mathrm{SFK}^{-/-} \mathrm{BM}$ cells appears to be due to the loss of Lyn, because only the deficiency of Lyn, but not Hck or Fgr, recapitulates long-term stem cell defect observed in mice transplanted with $\mathrm{SFK}^{-1-} \mathrm{BM}$ cells. Our results reveal an essential role for Lyn kinase in positively regulating long-term and multilineage engraftment of stem cells.

\section{Materials and methods}

Mice

Mice lacking various members of hematopoietic-specific SFKs (Hck, Fgr, and Lyn) have been backcrossed into C57BL/6 strain (CD45.2 allele) for more than 20 generations [27,28]. Mice lacking the expression of different combinations of the three hematopoietic-specific Src kinases have been generated and used in these studies: $\mathrm{Lyn}^{-/}, \mathrm{Fgr}^{-/}, \mathrm{Hck}^{-/-}$, and $\mathrm{Lyn} / \mathrm{Fgr} / \mathrm{Hck}^{-/-}\left(\mathrm{SFK}^{-/-}\right)$. "SFK knockout" (SFK KO) will be used hereafter to collectively

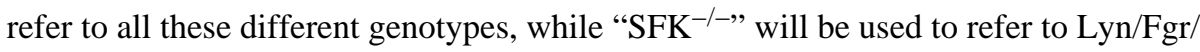
$\mathrm{Hck}^{-1-}$. Congenic C57BL/6 (CD45.2 allele) and B6.BoyJ mice (CD45.1 allele) were purchased from Jackson Laboratories (Bar Harbor, ME, USA) and maintained in our animal facility and used between 8 to 12 weeks of age. The Indiana University School of Medicine Institutional Animal Care and Use Committee approved all studies.

\section{Flow-cytometric analysis}

Low-density BM cells (LDBM) from the different SFK KO mice were stained with CD45.2fluorescein isothiocyanate (FITC), Sca-1-phycoerythrin (PE), and one of the following antibodies to analyze adhesion molecule phenotype: CD43-biotin (clone S7), CD49D-biotin (clone 9C10), CD49e-biotin (clone 5H10-27; MFR5), or CD62L-biotin (clone MEL-14). Biotinylated antibodies were developed with streptavidin-allophycocyanin (APC) (Molecular Probes, Eugene, OR, USA). Harvested BM and spleen from recipients of SFK 
KO cells in homing studies were stained with CD45.2-FITC and CD45.1-PE to determine chimerism, and then separately with CD45.2-FITC, Sca-1-PE, and anti-adhesion molecule antibodies as described here. All antibodies were from BD Pharmingen (San Diego, CA, USA). Cells were analyzed using a FACSCalibur (Becton Dickinson Immunocytometry Systems [BDIS], San Jose, CA, USA).

\section{Harvesting and purification of Lin- BM cells}

$\mathrm{BM}$ cells were flushed from the tibias and femurs of SFK KO mice, WT, and B6.BoyJ mice using Iscove's modified Dulbecco's media (Invitrogen, Carlsbad, CA, USA) containing 5\% fetal calf serum (FCS; Hyclone Laboratories, Logan, UT, USA). LDBM cells were prepared by centrifugation on Ficoll-Hypaque (density, 1.119; Sigma, St Louis, MO, USA). B6.BoyJ LDBM cells were used as competitor cells for all competitive repopulation experiments. $\mathrm{Lyn}^{-/-}, \mathrm{Hck}^{-/-}, \mathrm{Fgr}^{-/-}$, and $\mathrm{SFK}^{-/-}$LDBM cells were used as test cells in at least two independent experiments.

Lineage depletion was performed using the Easy Sep procedure from Stem Cell Technologies (Vancouver, BC, Canada). Briefly, LDBM cells were stained with biotinylated anti-mouse monoclonal antibodies specific for mature cell lineage antigens CD45R (B220, clone RA3-6B2), Gr-1 (Ly-6G, clone RB6-8C5), CD4 (L3T4, clone RM4-5), CD8a (Ly-2, clone 53-6.7), Ter119 and Mac-1 (CD11b, clone M1/70) (all purchased from Pharmingen) at a concentration of $1 \mathrm{uL}$ per $10^{6}$ cells. Cells were incubated at $4^{\circ} \mathrm{C}$ for 20 minutes and washed once with 10-fold excess of buffer, per manufacturer's recommendation. Thereafter, cells were resuspended and incubated with EasySep mouse biotin selection cocktail (Stem Cell Technologies) at a concentration of $1.0 \mathrm{uL}$ per $10^{6}$ cells for 15 minutes at $4^{\circ} \mathrm{C}$. Next, magnetic nanoparticles were added at a concentration of $0.5 \mathrm{uL}$ per $10^{6}$ cells for 10 minutes at $25^{\circ} \mathrm{C}$ and cells were subjected to a magnet three more times. Lineage-depleted cells were stained with APC rat anti-mouse CD117 (c-Kit) and PE-conjugated rat anti-mouse Sca-1 (both from Pharmingen). Negative controls were stained with PE-conjugated IgG2a and FITC-conjugated IGg2b. Based on these controls, $\mathrm{Lin}^{-} \mathrm{c}-\mathrm{Kit}^{+} \mathrm{Sca}-1^{+}$cells were isolated with a fluorescence-activated cell sorted (FACStar Plus, BDIS) under sterile conditions. Purity of Lin ${ }^{-} \mathrm{Sca}-{ }^{+}{ }^{+}$- $-\mathrm{Kit}^{+}$cells was $>99 \%$.

\section{Competitive repopulation experiments}

Ten to 12-week-old mice were lethally irradiated (1100-cGy split dose) before transplantation as described previously [29,30]. Limiting dilutions of LDBM $\left(1 \times 10^{5}\right.$ to $3 \times$ $10^{5}$ ) or c-Kit ${ }^{+} \mathrm{Sca}-1^{+} \mathrm{Lin}^{-}$cells $(1000$ to 10,000$)$ from WT, $\mathrm{Hck}^{-/}, \mathrm{Fgr}^{-/}, \mathrm{Lyn}^{-/-}$, and $\mathrm{SFK}^{-1-}$ mice were mixed with a constant number of B6. BoyJ LDBM cells $\left(1 \times 10^{5}\right)$. Each cell mixture was resuspended in $0.5 \mathrm{~mL}$ Iscove's modified Dulbecco's media $2 \%$ FCS and injected into the tail vein of lethally irradiated ( $950 \mathrm{cGy}$ administered in a single dose from a ${ }^{137} \mathrm{Cs} \gamma$-rradiator [Gamma Cell 40; Nordion International, Kanata, Ontario, Canada]) recipients.

\section{Chimerism analysis by fluorescence cytometry}

Tail vein blood samples $(100 \mathrm{uL})$ were obtained monthly post-transplantation for analysis of donor cell chimerism and multiline-age analysis. Peripheral blood cells were incubated in 
red blood cell lysis buffer for 5 minutes at $4^{\circ} \mathrm{C}$. Cells were washed twice, resuspended in phosphate-buffered saline $0.1 \%$ bovine serum albumin, and aliquoted into eight individual tubes for antibody staining. Each sample was stained with CD45.2-FITC (C57BL/6) and CD45.1-PE (B6.BoyJ strain) plus four individual lineage markers conjugated to PE/APC at $4^{\circ} \mathrm{C}$ for 20 minutes. Samples were washed twice and resuspended in phosphate-buffered saline $0.1 \%$ bovine serum albumin before analysis by fluorescence cytometry. All data were analyzed using CELL Quest software (BDIS).

\section{Homing studies}

The ability of different SFK KO HSC/Ps to home to the BM and spleen following intravenous infusion was analyzed in short-term tracking studies as described previously [30]. Grafts consisted of LDBM cells, or purified Sca- $1^{+} \mathrm{Lin}^{-}\left(\mathrm{CD}^{-}, \mathrm{B} 220^{-}, \mathrm{Gr}-1^{-}\right)$and Sca- $1^{+} \mathrm{Lin}^{+}\left(\mathrm{CD}^{+}, \mathrm{B} 220^{+}, \mathrm{Gr}-1^{+}\right)$cells isolated by flow-cytometric cell sorting using Sca-1FITC and lineage antibodies in APC. Sca- $1^{+} \mathrm{Lin}^{-}$and $\mathrm{Sca}-1^{+} \mathrm{Lin}^{+}$cells were used as grafts to compare the homing of two BM populations with opposing levels of hematopoietic potential. Briefly, $17.5 \times 10^{6}$ to $20 \times 10^{6} \mathrm{LDBM}$ cells or $0.14 \times 10^{6}$ to $0.16 \times 10^{6}$ Sca- $1^{+} \mathrm{Lin}^{-}$and $\mathrm{Sca}-{ }^{+} \mathrm{Lin}^{+}$cells, isolated from WT C57/BL6 or SFK ${ }^{-/}$mice (CD45.2 allele) were injected into lethally irradiated B6.SJL-ptrca Pep3b/BoyJ (B6.BoyJ) mice (CD45.1 allele) 1 hour to 4 hours after radiation. Recipients were sacrificed 16 to 19 hours later, and single-cell suspensions from BM and spleen were lysed and analyzed for recovery of HSC/Ps.

\section{Calculation of recovery of primitive donor cells}

Frequency of donor cells falling within a light scatter gate including lymphocytes and large granular cells was determined for each harvested tissue based on the background fluorescence of cells from unmanipulated mice. Frequencies were multiplied by the total number of cells in each tissue, and then divided by the number of cells in the original graft to calculate the recovery of transplanted cells. For LDBM transplants only, frequency of Sca- $1^{+}$cells among donor cells was also determined and used in conjunction with tissue cellularity to calculate recovery of Sca- $1^{+}$cells.

\section{Results}

\section{Primitive phenotype of SFK KO cells}

To begin to understand the HSC/P cell phenotype of the different SFK KO cells, we first characterized the BM phenotype of SFK KO cells by examining the expression of Sca-1, lineage markers, c-Kit, and a pattern of adhesion molecules known to be expressed on murine long-term engrafting cells, specifically CD43 ${ }^{+} \mathrm{CD} 49^{+} \mathrm{CD} 2 \mathrm{~L}^{-}$[29]. Figure $1 \mathrm{~A}$ depicts the percentage of Sca- $1^{+}$cells in $\mathrm{SFK}^{-/-} \mathrm{BM}$, which is significantly less than WT $\mathrm{BM}$ cells, whereas no differences were found for the other Src kinase mutants. Because overall BM cellularity was similar (data not shown), absolute number of $\mathrm{SFK}^{-/-} \mathrm{BM} \mathrm{Sca-1}{ }^{+}$ cells was also decreased compared to WT. Despite low numbers of Sca- ${ }^{+}$cells in $\mathrm{SFK}^{-/-}$ mice, the fraction of these cells that exhibited a primitive phenotype (Lin-, c-Kit ${ }^{+}, \mathrm{CD}^{4} 3^{+}$, $\mathrm{CD} 49 \mathrm{e}^{+}, \mathrm{CD}_{2} \mathrm{~L}^{-}$) was significantly increased in $\mathrm{SFK}^{-/}$mice, as well as in $\mathrm{Lyn}^{-1-}$ mice (Figs. 1B to 1F) compared to WT BM cells. These results suggest that deficiency of three 
Src kinases collectively or of Lyn kinase alone results in increased numbers of cells with an immunophenotype known to be enriched in long-term repopulating cells.

\section{$\mathrm{SFK}^{-/-} \mathrm{BM}$ cells differentially regulate the growth of progenitors in response to cytokines}

Previous studies have shown that multiple hematopoietic cytokines use Src kinases for growth and survival, however, most of these studies have been conducted in cell lines utilizing dominant negative and/or activated versions of Src kinases. Because we observed an increase in the number of $\mathrm{BM}$ progenitors with a primitive immunophenotype in $\mathrm{SFK}^{-/}$ mice, we next assessed the growth potential of $\mathrm{SFK}^{-1}$ BM cells in response to various cytokines. As seen in Figure 2A, a significant increase in the number of colony-forming units in culture (CFU-C) is observed in $\mathrm{SFK}^{-/-} \mathrm{BM}$ cells when grown in the presence of GCSF. In contrast, CFU-C generation in the presence of IL-3, SCF, or a combination of five different cytokines, including SCF, erythropoietin, G-CSF, IL-3, and thrombopoietin was significantly reduced in these same cells compared to control cells. GM-CSF stimulation showed no significant difference in colony formation in any group under these conditions. Consistent with the reduced clonogenic potential of $\mathrm{SFK}^{-/-} \mathrm{BM}$ cells in the presence of IL-3, SCF, and the combination of five cytokines, the clonogenic potential of phenotypically defined $\mathrm{KIT}^{+}$Lin-Sca- ${ }^{+}$(KLS) $\mathrm{SFK}^{-/-}$BM cells was also significantly reduced compared to WT controls $\left(74 \pm 12[\mathrm{WT}]\right.$ vs $\left.29 \pm 12\left[\mathrm{SFK}^{-/}\right], \mathrm{n}=4,{ }^{*} p<0.05\right)$. Likewise, a significant reduction in the generation of high proliferative potential CFCs was also noted in $\mathrm{SFK}^{-/}$ KLS cells $\left(27 \pm 8[\mathrm{WT}]\right.$ vs $\left.9 \pm 3\left[\mathrm{SFK}^{-/}\right], \mathrm{n}=3,{ }^{*} p<0.05\right)$. Consistently, thymidine incorporation assay utilizing the same population of $\mathrm{SFK}^{-/}$cells also revealed a significant reduction in thymidine uptake in $\mathrm{SFK}^{-/-} \mathrm{KLS}$ cells compared to WT controls $(42,099 \pm$ 4709 [counts per minute] WT vs $16176 \pm 1469$ [counts per minute] $\mathrm{SFK}^{-/-},{ }^{*} p<0.05$ ). To further explore the clonogenic potential of SFK ${ }^{-/-}$BM cells to G-CSF and GM-CSF, we conducted additional experiments in the presence of a range of cytokine concentrations. As shown in Figure 2B, G-CSF stimulation of $\mathrm{SFK}^{-/-}$BM cells at all concentrations tested gave rise to significantly more CFU-Cs. In contrast, GM-CSF stimulation of these same cell groups resulted in either similar number of CFU-Cs or reduced CFU-Cs at lower concentrations. We also examined the growth potential of SFK ${ }^{-1-} \mathrm{BM}$ cells to M-CSF and found a significant increase in colony formation compared to control cells (Fig. 2B). Taken together, these results suggest that deficiency of SFKs differentially regulates the growth of BM hematopoietic progenitors.

\section{Competitive repopulating ability of $\mathrm{SFK}^{-/-} \mathrm{HSC} / \mathrm{Ps}$ compared to WT controls}

Given the differential response of $\mathrm{SFK}^{-/}$BM cells to cytokines and the presence of increased numbers of relatively primitive progenitors in the $\mathrm{BM}$ of $\mathrm{SFK}^{-/-}$mice, we examined the long-term repopulating potential of $\mathrm{SFK}^{-1-} \mathrm{BM}$ cells. To this end, $\mathrm{SFK}^{-/-}$and WT cells were assayed in a competitive repopulation assay using three different test to competitor cell ratios. Regardless of whether LDBM or KLS cells were used as test cells, $\mathrm{SFK}^{-/-}$cells consistently exhibited reduced chimerism compared to WT cells 6 months posttransplantation (Fig. 3A and C). To determine if this effect is sustained upon secondary transplantation and at the level of stem cells, marrow of mice transplanted with either the WT or $\mathrm{SFK}^{-/}$LDBM cells (Fig. 3A) at a test to competitor ratio of 1:3 were harvested 6 months post primary transplantation, and $1 \times 10^{6} \mathrm{LDBM}$ donor cells were injected to 
lethally irradiated secondary recipients. As shown in Figure 3B, the reduced chimerism was apparent in secondary recipients 6 months posttransplantation. These results suggest that loss of SFKs in BM cells impairs the long-term repopulating ability of stem cells. Consistent with the enhanced CFU-C generation observed in the presence of G-CSF and M-CSF in vitro, a lineage bias towards the generation of Gr-1/Mac-1-positive cells was observed in mice transplanted with $\mathrm{SFK}^{-/}$BM cells compared to controls in both primary and secondary recipients (data not shown).

\section{Homing properties of $\mathrm{SFK}^{-/-}$cells}

We next assessed whether the reduced repopulating ability of $\mathrm{SFK}^{-/}$stem cells was due in part to reduced homing of these cells to the marrow. To do this, we investigated whether Hck, Fgr, and Lyn are important in trafficking of HSC/P cells to the BM following intravenous transplantation. LDBM grafts of the various Src mutants were prepared and transplanted into lethally irradiated syngeneic recipients. Sixteen to 19 hours later, recovery of total cells and primitive phenotypes was determined in recipient $\mathrm{BM}$ and spleen. Figures $4 \mathrm{~A}$ and $\mathrm{B}$ show that total and Sca- ${ }^{+} \mathrm{SFK}^{-1-}$ cells, respectively, homed in significantly higher numbers than WT to recipient BM. Interestingly, while the other SFK KO genotypes did not differ in homing to $\mathrm{BM}, \mathrm{Lyn}^{-/}$cells exhibited significantly poor homing to spleen (Figs. 4C and D).

Expression of adhesion molecules involved in primitive hematopoiesis was also examined on BM- and spleen-homed cells as an additional measure of primitive HSC/P homing. As shown in Figures 5A and D, expression of CD43 and CD49e was higher on BM- and spleenhomed $\mathrm{Lyn}^{-/-}$and $\mathrm{SFK}^{-/-}$cells, suggesting that Lyn may be the predominant molecule involved in vivo trafficking of $\mathrm{HSC} / \mathrm{P}$ cells.

\section{Homing of purified Sca-1+Lin- and Sca-1+Lin+ cells}

We have previously shown that purified phenotypically defined BM cells, known to be enriched for long-term engraftment potential $\left(\mathrm{Sca}-1^{+} \mathrm{lin}^{-} \mathrm{CD} 62 \mathrm{~L}^{-}\right.$or Sca- ${ }^{+} \mathrm{lin}^{-} \mathrm{CD} 49 \mathrm{e}^{+}$), home more efficiently to BM than cells lacking such potential $\left(\mathrm{Sca}-1^{+}{ }^{+} \mathrm{lin}^{-} \mathrm{CD} 62 \mathrm{~L}^{+}\right.$or Sca- $1^{+} \operatorname{lin}^{-} \mathrm{CD} 49 \mathrm{e}^{-}$), which segregate preferentially to the spleen [31]. This differential homing of HSC vs non-HSC illustrates some specificity of the homing process. To determine if a similar specificity of homing of primitive vs more mature $\mathrm{SFK}^{-1-} \mathrm{HSC} / \mathrm{Ps}$ exist, $\mathrm{Sca}-1^{+} \mathrm{Lin}^{-}$and Sca-1 ${ }^{+} \mathrm{Lin}^{+}$cells were isolated from $\mathrm{SFK}^{-/}$and WT BM and transplanted into lethally irradiated WT recipients. Sixteen to 19 hours later, recipients were sacrificed and BM and spleen examined for the presence of donor cells. Similar to our previously reported finding, recovery of WT Sca- $1^{+} \mathrm{Lin}^{-}$cells was significantly higher in BM (Fig. 6A), whereas recovery of Sca- $1^{+} \mathrm{Lin}^{+}$cells tended to be higher in spleen (Fig. 6B). However, recovery of either phenotype from $\mathrm{SFK}^{-1}$ mice did not differ in $\mathrm{BM}$ or spleen (Figs. 6C and D), suggesting that, based on known phenotypic definitions of primitive $\mathrm{HSC} / \mathrm{Ps}$, specificity of homing does not exist for $\mathrm{SFK}^{-/-}$primitive HSC/Ps in a manner similar to that of WT cells. 


\section{Lyn but not Fgr or Hck contributes to reduced repopulating potential of SFK-/- BM cells}

To determine which of the three SFKs contribute to impaired repopulating ability of $\mathrm{SFK}^{-/-}$ $\mathrm{BM}$ cells, we performed competitive repopulation assay using BM cells from individual knockouts of Lyn, Fgr, and Hck. These studies were done using equal number of competitor and marrow cells derived from each of the three single Src kinase mutants, Lyn, Hck, and Fgr. As seen in Figure 7A, no significant difference in the overall chimerism was observed in mice transplanted with HSC/P lacking Fgr or Hck compared to WT controls 4 months posttransplantation. In contrast, deficiency of Lyn kinase demonstrated a significant reduction in overall engraftment compared to WT controls. The decrease was observed in every lineage examined and was also apparent in secondary recipients (Fig. 7B, 8A/B). These results suggest that the reduced engraftment observed in $\mathrm{SFK}^{-1}$ primary and secondary recipients is likely contributed by the deficiency of Lyn Src kinase.

\section{Discussion}

Despite the involvement of multiple cytokines in regulating the activation of Src family kinases, including Lyn, Hck, and Fgr the role of these enzymes in modulating the growth, homing, and long-term engraftment of hematopoietic stem and progenitor cells is poorly understood. In this study, we have examined the role of SFKs in cytokine-mediated growth, homing, and long-term engraftment of HSC/Ps. We show increased numbers of phenotypically defined stem/progenitors in the $\mathrm{BM}$ of $\mathrm{Lyn}^{-/-}$and $\mathrm{SFK}^{-/-}$mice but not $\mathrm{Hck}^{-/-}$or $\mathrm{Fgr}^{-/-}$mice. The increase in the number of Sca- $1^{+} \mathrm{Lin}^{-}$cells in these mice is associated with increased colony-forming ability in response to M-CSF and G-CSF, but reduced growth in response to IL-3, SCF, and a combination of five cytokines. Although the short-term homing potential of $\mathrm{SFK}^{-/}$LDBM cells to the recipient BM is significantly enhanced compared to WT controls, the homing potential of $\mathrm{Sca}-1^{+} \mathrm{Lin}^{+}$or Sca- $1^{+} \mathrm{Lin}^{-}$ $\mathrm{SFK}^{-1-}$ cells is similar to that observed using WT Sca- $1^{+} \mathrm{Lin}^{+}$or Sca- $1^{+} \mathrm{Lin}^{-}$cells, although the homing specificity of $\mathrm{SFK}^{-/}$cells is lost. In contrast, we found that serial competitive repopulation with $\mathrm{SFK}^{-1-} \mathrm{BM}$ was deficient relative to WT BM, although defects observed in primary recipients were not augmented by secondary transplantation. Remarkably, the phenotypic defects associated with the deficiency of SFKs (i.e., Lyn, Hck, and Fgr) are due in large part to deficiency of Lyn Src kinase because loss of Lyn, but not Hck or Fgr, also manifests a similar stem cell defect as that seen in mice transplanted with $\mathrm{SFK}^{-/-} \mathrm{BM}$ cells.

Our results demonstrating the presence of fewer Sca- $1^{+}$cells, yet more primitive Sca- $1^{+} \mathrm{Lin}^{-}$ cells in the $\mathrm{BM}$ of $\mathrm{SFK}^{--}$mice, which posses reduced clonogenic and engrafting potential, but enhanced homing potential than their WT counterparts suggests that SFKs impact the function of different BM progenitors differently. Although the precise mechanism(s) by which SFKs impact these functions in the HSC/P compartment are unclear, previous studies have demonstrated that these kinases in addition to both positively and negatively regulating functions in the same cell type can also antagonize the function of each other. For example, significant evidence exists to suggest that in B cells, early responses to BCR cross-linking are altered in $\mathrm{Lyn}^{-/-}$mice, supporting a role for Lyn in the initiation of signaling via the BCR [20,21,23]. Intriguingly, Lyn-deficient B cells are also hyperresponsive to anti-IgMinduced proliferation and demonstrate enhanced activation of mitogen-activated protein 
kinase and sustained calcium mobilization [21-23,26]. Hernandez-Hansen et al. [32] have shown that dysregulated signaling in Lyn-deficient mast cells is due in part to enhanced Fyn activation, and a recent study by Hong et al [33] suggested that the Src kinase Hck regulates mast cell activation by suppressing activation of Lyn. These results suggest that regulation of SFKs in HSC/Ps is likely to be complex and may depend on the stimulus and development stage of the cells under investigation. Thus, the functional consequences of SFK activation may be context-dependent. We believe that the complex functional outcomes observed in the various HSC/P compartments reported in this article are likely to be a result of complex modes of SFK regulation.

Previous studies using Lyn-deficient mice have shown Lyn to play an essential role in maintaining signaling thresholds in B cells $[21,25,26]$, myeloid cells, including in mast cells [14,19,34-37]. Loss of Lyn results in reduced activation of phosphatases, such as SHIP, which results in hypersensitivity to cytokines $[19,24,25]$. In both B cells as well as mast cells, loss of Lyn results in hyperactivation of AKT and the mitogen-activated protein kinase extracellular signal-regulated kinase. In macrophages, loss of Lyn results in hypersensitivity to GM-CSF and M-CSF [19,34]. Previous studies have also shown that deficiency of Lyn in aged mice results in extramedullary hematopoiesis, as well as macrophage tumors in some cases $[19,38]$. Our studies reveal a positive role for Lyn in regulating long-term engraftment of stem cells. We show that loss of Lyn in primitive HSC/P cells results in reduced engraftment in both primary and secondary recipient mice. Although the mechanism by which loss of Lyn impacts stem cell engraftment is not known, this is likely to occur as a result of reduced responsiveness to cytokines as demonstrated by reduced colony-forming ability of $\mathrm{SFK}^{-/-}$BM cells as well as more primitive cells in both a methylcellulose assay as well as in a short-term liquid culture assay.

Reduced competitive repopulating potential of $\mathrm{SFK}^{-1-} \mathrm{KLS}$ fraction, despite a marked increase in the number of $\mathrm{Lin}^{-} \mathrm{Sca}-1^{+}$cells in the $\mathrm{BM}$ of $\mathrm{SFK}^{-1-}$ mice, suggests that the surface phenotype of BM cells may not necessarily reflect their function in vivo. It is conceivable that alterations in the BM microenvironment as a result of SFK deficiency may alter the phenotypic characteristics of BM cells. Our data demonstrating differences in the expression of various critical adhesion molecules known to be associated with the engraftment and homing potential of WT stem/progenitor cells clearly illustrates this point. Others have also reported a lack of correlation between phenotypic markers and function of stem cells in both mutant mice as well as upon perturbing normal steady-state hematopoiesis [39-43].

An alternate, but unlikely possibility to explain the increase in the number of relatively immature $\mathrm{HSC} / \mathrm{P}$ cells in the $\mathrm{BM}$ of $\mathrm{SFK}^{-/}$mice could be attributed to microenvironmental changes in these mice. The analysis of primitive cells derived from mice carrying deletion of genes in every tissue, such as the ones described in the present study, does not allow for assessment of cell intrinsic vs extrinsic contributions to HSC/P functions. Although SFKs, Hck, Fgr, and Lyn are hematopoietic-specific, we have previously demonstrated that loss of these kinases collectively results in a BM environment that is more proteolytic than that of their WT counterpart [4]. Although, these modest changes in the level of proteases in the $\mathrm{BM}$ of $\mathrm{SFK}^{-/-}$mice did not result in changes in the engraftment potential of WT BM cells 
when transplanted into $\mathrm{SFK}^{-/-}$recipients, we cannot rule out the subtle effects of a proteolytic BM environment on the genesis of stem/progenitor cells or for the necessary support to maintain the function of these cells prior to transplantation. Generation of conditional knockout mice in which Src kinases are specifically deleted in the stem/ progenitor cell compartment should help us address this issue in the future.

Our results demonstrating a lack of homing defect either in whole BM or $\mathrm{Lin}^{-} \mathrm{Sca}-1^{+}$ $\mathrm{SFK}^{-/-}$or $\mathrm{Lyn}^{-/-}$cells are intriguing. Ptasznik et al. [44] recently demonstrated a biochemical interaction between CXCR4 and Lyn Src kinase in normal BM progenitors. They showed that CXCR4-dependent stimulation of Lyn kinase is associated with the activation of phosphatidylinositol 3 kinase and loss of Lyn Src kinase in BMLD cells (i.e., $\mathrm{Lyn}^{-/-} \mathrm{BM}$ cells) impairs stromal-derived factor-1-induced migration in vitro by as much as $70 \%$ compared to control cells. Although in their studies, stromal-derived factor-1-mediated inhibition in migration was not complete; our in vivo short-term homing studies using both $\mathrm{SFK}^{-/-}$or $\mathrm{Lyn}^{-/-} \mathrm{LDBM}$ cells demonstrate enhanced recovery of these cells in the BM of lethally irradiated recipients. Furthermore, fractionation of $\mathrm{SFK}^{-/} \mathrm{LDBM}$ cells into Sca- $1^{+} \mathrm{Lin}^{+}$and Sca- ${ }^{+} \mathrm{Lin}^{-}$cells did not reveal significant differences in the homing potential of these cells compared to WT control cells. Thus, although in vitro migration of $\mathrm{Lyn}^{-1-}$ LDBM cells in response to stromal-derived factor- 1 has been shown to be altered, in vivo this alteration is not sufficient to affect the homing potential of $\mathrm{SFK}^{-/-}$or $\mathrm{Lyn}^{-/-} \mathrm{BM}$ cells under the experimental conditions employed in the present study [44]. In summary, our studies highlight an essential role for Src kinases in regulating cell-intrinsic growth and engraftment of HSC/P cells and provide new insight into cytokine signaling during hematopoiesis.

\section{Acknowledgments}

Supported by grants R01 HL075816 (to R.K) and R01 HL75660 (to C.O.)

We thank Marilyn Wales for assistance in preparation of the manuscript and expert administrative assistance.

\section{References}

1. Lannutti BJ, Drachman JG. Lyn tyrosine kinase regulates thrombopoietin-induced proliferation of hematopoietic cell lines and primary megakaryocytic progenitors. Blood. 2004; 103:3736-3743. [PubMed: 14726379]

2. Lannutti BJ, Minear J, Blake N, Drachman JG. Increased megakaryo-cytopoiesis in Lyn-deficient mice. Oncogene. 2006; 25:3316-3324. [PubMed: 16418722]

3. Lannutti BJ, Shim MH, Blake N, Reems JA, Drachman JG. Identification and activation of Src family kinases in primary megakaryocytes. Exp Hematol. 2003; 31:1268-1274. [PubMed: 14662334]

4. Borneo J, Munugalavadla V, Sims EC, et al. Src family kinase-mediated negative regulation of hematopoietic stem cell mobilization involves both intrinsic and microenvironmental factors. Exp Hematol. 2007; 35:1026-1037. [PubMed: 17588471]

5. Mermel CH, McLemore ML, Liu F, et al. Src family kinases are important negative regulators of GCSF-dependent granulopoiesis. Blood. 2006; 108:2562-2568. [PubMed: 16772601]

6. Santini V, Scappini B, Indik ZK, Gozzini A, Ferrini PR, Schreiber AD. The carboxy-terminal region of the granulocyte colony-stimulating factor receptor transduces a phagocytic signal. Blood. 2003; 101:4615-4622. [PubMed: 12586631] 
7. Ward AC, Monkhouse JL, Csar XF, Touw IP, Bello P. The Src-like tyrosine kinase Hck is activated by granulocyte colony-stimulating factor (G-CSF) and docks to the activated G-CSF receptor. Biochem Biophys Res Commun. 1998; 251:117-123. [PubMed: 9790917]

8. Torigoe T, O'Connor R, Santoli D, Reed JC. Interleukin-3 regulates the activity of the LYN proteintyrosine kinase in myeloid-committed leukemic cell lines. Blood. 1992; 80:617-624. [PubMed: 1638019]

9. Hibbs ML, Harder KW. The duplicitous nature of the Lyn tyrosine kinase in growth factor signaling. Growth Factors. 2006; (Suppl):1. [PubMed: 16393690]

10. Sampson M, Zhu QS, Corey SJ. Src kinases in G-CSF receptor signaling. Front Biosci. 2007; 12:1463-1474. [PubMed: 17127394]

11. Zhu QS, Robinson LJ, Roginskaya V, Corey SJ. G-CSF-induced tyro-sine phosphorylation of Gab2 is Lyn kinase dependent and associated with enhanced Akt and differentiative, not proliferative, responses. Blood. 2004; 103:3305-3312. [PubMed: 14656892]

12. Zhu QS, Xia L, Mills GB, Lowell CA, Touw IP, Corey SJ. G-CSF induced reactive oxygen species involves Lyn-PI3-kinase-Akt and contributes to myeloid cell growth. Blood. 2006; 107:18471856. [PubMed: 16282349]

13. Robinson LJ, Xue J, Corey SJ. Src family tyrosine kinases are activated by Flt3 and are involved in the proliferative effects of leukemia-associated Flt3 mutations. Exp Hematol. 2005; 33:469-479. [PubMed: 15781338]

14. Hernandez-Hansen V, Mackay GA, Lowell CA, Wilson BS, Oliver JM. The Src kinase Lyn is a negative regulator of mast cell proliferation. J Leukoc Biol. 2004; 75:143-151. [PubMed: 14525964]

15. Chin H, Arai A, Wakao H, Kamiyama R, Miyasaka N, Miura O. Lyn physically associates with the erythropoietin receptor and may play a role in activation of the Stat5 pathway. Blood. 1998; 91:3734-3754. [PubMed: 9573010]

16. Shivakrupa R, Linnekin D. Lyn contributes to regulation of multiple Kit-dependent signaling pathways in murine bone marrow mast cells. Cell Signal. 2005; 17:103-109. [PubMed: 15451030]

17. Korade-Mirnics Z, Corey SJ. Src kinase-mediated signaling in leukocytes. J Leukoc Biol. 2000; 68:603-609. [PubMed: 11073097]

18. Xu Y, Harder KW, Huntington ND, Hibbs ML, Tarlinton DM. Lyn tyrosine kinase: accentuating the positive and the negative. Immunity. 2005; 22:9-18. [PubMed: 15664155]

19. Harder KW, Parsons LM, Armes J, et al. Gain- and loss-of-function Lyn mutant mice define a critical inhibitory role for Lyn in the myeloid lineage. Immunity. 2001; 15:603-615. [PubMed: 11672542]

20. Hibbs ML, Tarlinton DM, Armes J, et al. Multiple defects in the immune system of Lyn-deficient mice, culminating in autoimmune disease. Cell. 1995; 83:301-311. [PubMed: 7585947]

21. Chan VW, Meng F, Soriano P, DeFranco AL, Lowell CA. Characterization of the B lymphocyte populations in Lyn-deficient mice and the role of Lyn in signal initiation and down-regulation. Immunity. 1997; 7:69-81. [PubMed: 9252121]

22. Nishizumi H, Horikawa K, Mlinaric-Rascan I, Yamamoto T. A double-edged kinase Lyn: a positive and negative regulator for antigen receptor-mediated signals. J Exp Med. 1998; 187:13431348. [PubMed: 9547345]

23. Nishizumi H, Taniuchi I, Yamanashi Y, et al. Impaired proliferation of peripheral B cells and indication of autoimmune disease in lyn-deficient mice. Immunity. 1995; 3:549-560. [PubMed: 7584145]

24. Smith KG, Tarlinton DM, Doody GM, Hibbs ML, Fearon DT. Inhibition of the B cell by CD22: a requirement for Lyn. J Exp Med. 1998; 187:807-811. [PubMed: 9480991]

25. Cornall RJ, Cyster JG, Hibbs ML, et al. Polygenic autoimmune traits: Lyn, CD22, and SHP-1 are limiting elements of a biochemical pathway regulating BCR signaling and selection. Immunity. 1998; 8:497-508. [PubMed: 9586639]

26. Chan VW, Lowell CA, DeFranco AL. Defective negative regulation of antigen receptor signaling in Lyn-deficient B lymphocytes. Curr Biol. 1998; 8:545-553. [PubMed: 9601638] 
27. Meng F, Lowell CA. Lipopolysaccharide (LPS)-induced macrophage activation and signal transduction in the absence of Src-family kinases Hck, Fgr, and Lyn. J Exp Med. 1997; 185:16611670. [PubMed: 9151903]

28. Meng F, Lowell CA. A beta 1 integrin signaling pathway involving Src-family kinases, $\mathrm{Cbl}$ and PI-3 kinase is required for macrophage spreading and migration. EMBO J. 1998; 17:4391-4403. [PubMed: 9687507]

29. Orschell-Traycoff CM, Hiatt K, Dagher RN, Rice S, Yoder MC, Srour EF. Homing and engraftment potential of Sca-1(+)lin(-) cells fractionated on the basis of adhesion molecule expression and position in cell cycle. Blood. 2000; 96:1380-1387. [PubMed: 10942381]

30. Plett PA, Frankovitz SM, Orschell-Traycoff CM. In vivo trafficking, cell cycle activity, and engraftment potential of phenotypically defined primitive hematopoietic cells after transplantation into irradiated or nonirradiated recipients. Blood. 2002; 100:3545-3552. [PubMed: 12411318]

31. Plett PA, Frankovitz SM, Orschell CM. Distribution of marrow repopulating cells between bone marrow and spleen early after transplantation. Blood. 2003; 102:2285-2291. [PubMed: 12775569]

32. Hernandez-Hansen V, Smith AJ, Surviladze Z, et al. Dysregulated FcepsilonRI signaling and altered Fyn and SHIP activities in Lyn-deficient mast cells. J Immunol. 2004; 173:100-112. [PubMed: 15210764]

33. Hong H, Kitaura J, Xiao W, et al. The Src family kinase Hck regulates mast cell activation by suppressing an inhibitory Src family kinase Lyn. Blood. 2007; 110:2511-2519. [PubMed: 17513616]

34. Baran CP, Tridandapani S, Helgason CD, Humphries RK, Krystal G, Marsh CB. The inositol $5^{\prime}-$ phosphatase SHIP-1 and the Src kinase Lyn negatively regulate macrophage colony-stimulating factor-induced Akt activity. J Biol Chem. 2003; 278:38628-38636. [PubMed: 12882960]

35. Malbec O, Fong DC, Turner M, et al. Fc epsilon receptor I-associated lyn-dependent phosphorylation of $\mathrm{Fc}$ gamma receptor IIB during negative regulation of mast cell activation. $\mathrm{J}$ Immunol. 1998; 160:1647-1658. [PubMed: 9469421]

36. Kawakami Y, Kitaura J, Satterthwaite AB, et al. Redundant and opposing functions of two tyrosine kinases, Btk and Lyn, in mast cell activation. J Immunol. 2000; 165:1210-1219. [PubMed: 10903718]

37. Kitaura J, Asai K, Maeda-Yamamoto M, Kawakami Y, Kikkawa U, Kawakami T. Akt-dependent cytokine production in mast cells. J Exp Med. 2000; 192:729-740. [PubMed: 10974038]

38. Harder KW, Quilici C, Naik E, et al. Perturbed myelo/erythropoiesis in Lyn-deficient mice is similar to that in mice lacking the inhibitory phosphatases SHP-1 and SHIP-1. Blood. 2004; 104:3901-3910. [PubMed: 15339845]

39. Walkley CR, Shea JM, Sims NA, Purton LE, Orkin SH. Rb regulates interactions between hematopoietic stem cells and their bone marrow microenvironment. Cell. 2007; 129:1081-1095. [PubMed: 17574022]

40. Purton LE, Dworkin S, Olsen GH, et al. RARgamma is critical for maintaining a balance between hematopoietic stem cell self-renewal and differentiation. J Exp Med. 2006; 203:1283-1293. [PubMed: 16682494]

41. Spangrude GJ, Brooks DM, Tumas DB. Long-term repopulation of irradiated mice with limiting numbers of purified hematopoietic stem cells: in vivo expansion of stem cell phenotype but not function. Blood. 1995; 85:1006-1016. [PubMed: 7849289]

42. Tajima F, Sato T, Laver JH, Ogawa M. CD34 expression by murine hematopoietic stem cells mobilized by granulocyte colony-stimulating factor. Blood. 2000; 96:1989-1993. [PubMed: 10961905]

43. Walkley CR, Fero ML, Chien WM, Purton LE, McArthur GA. Negative cell-cycle regulators cooperatively control self-renewal and differentiation of haematopoietic stem cells. Nat Cell Biol. 2005; 7:172-178. [PubMed: 15654333]

44. Ptasznik A, Urbanowska E, Chinta S, et al. Crosstalk between BCR/ABL oncoprotein and CXCR4 signaling through a Src family kinase in human leukemia cells. J Exp Med. 2002; 196:667-678. [PubMed: 12208881] 
A
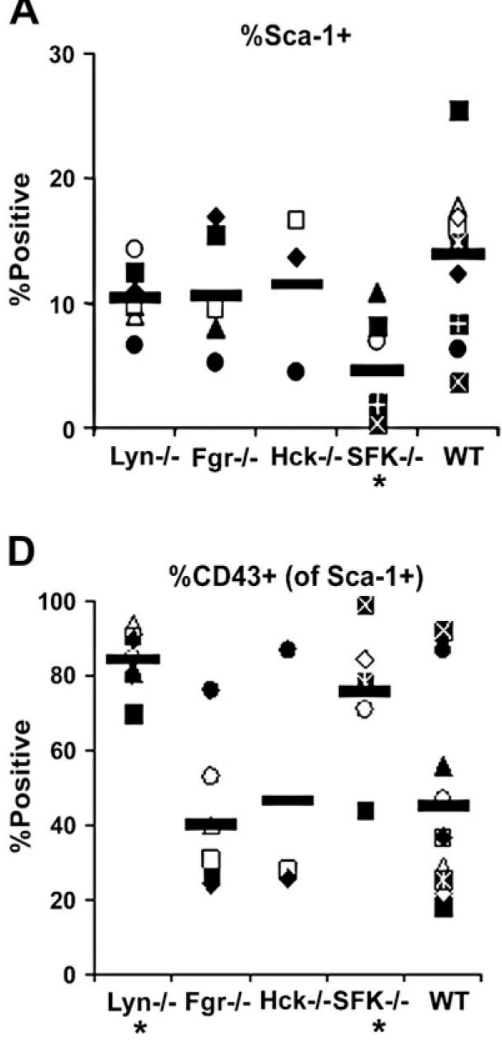

B

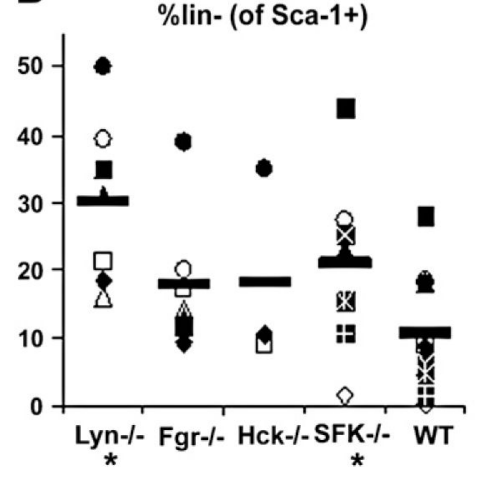

E

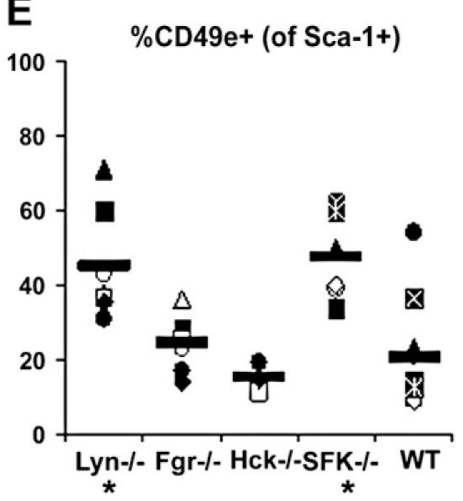

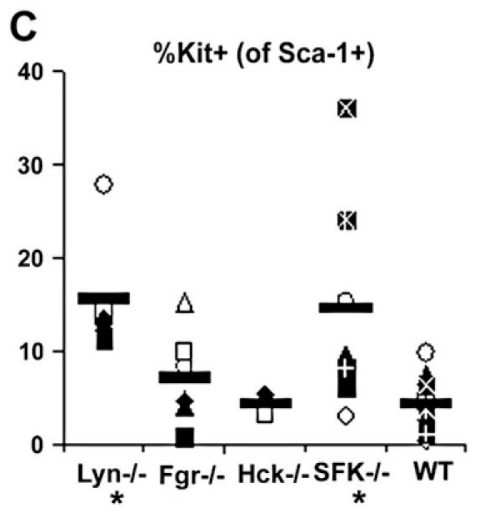

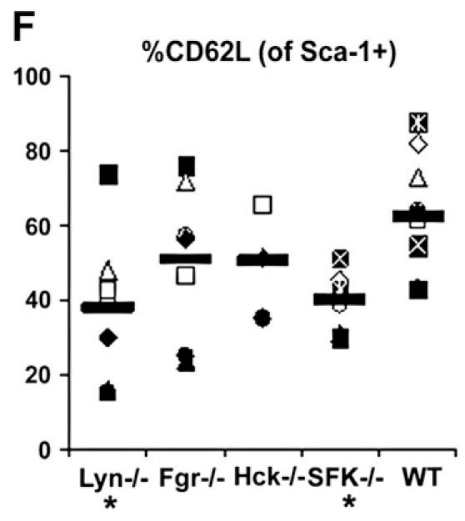

Figure 1.

Primitive phenotype of Src family kinase (SFK) knockout cells. Low-density bone marrow (LDBM) cells from SFK knockout mice were analyzed for percentage of Sca- $1^{+}$cells and markers known to be expressed on primitive hematopoietic cells. (A) Percentage of Sca- $1^{+}$ cells within LDBM cells. Percentages of Sca- $1^{+}$cells lacking lineage markers (CD3, B220, Gr-1, B), or expressing KIT (C), CD43 (D), CD49e (E), or CD62L (F) are shown in the remaining graphs. Data are from individual mice in 3 to 11 separate experiments; mean is given by horizontal line. ${ }^{*} p<0.05$ compared with wild-type (WT). 
A

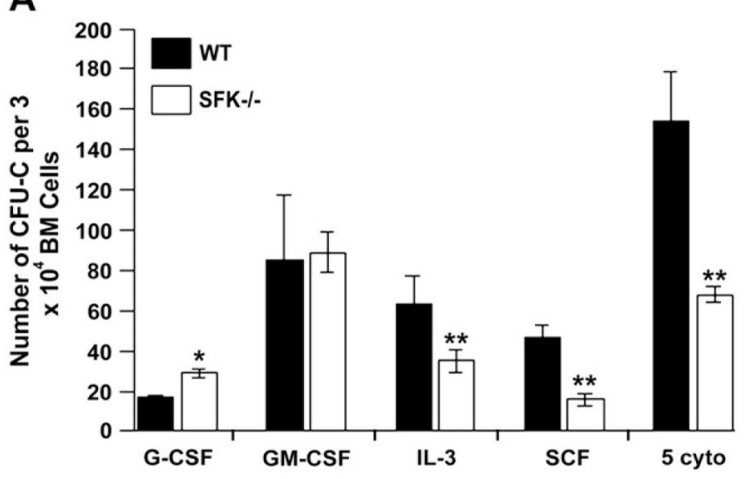

B

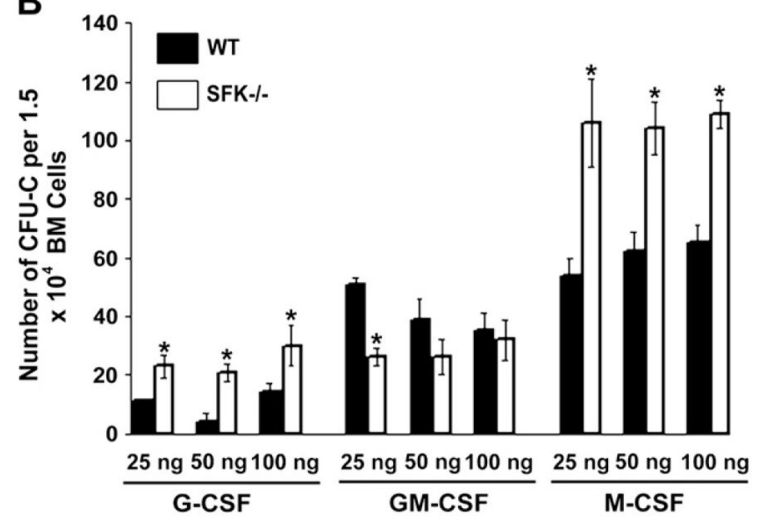

Figure 2.

Deficiency of Src family kinases (SFKs) in bone marrow (BM) cells results in different responses to cytokines. Low-density BM (LDBM) cells from wild-type (WT) or $\mathrm{SFK}^{-/}$ mice were harvested and subjected to methylcellulose assay. (A) $3 \times 10^{4} \mathrm{LDBM}$ cells were grown in methylcellulose in the presence of granulocyte colony-stimulated factor (G-CSF; $25 \mathrm{ng} / \mathrm{mL}$ ), granulocyte macrophage colony-stimulating factor (GM-CSF; $50 \mathrm{ng} / \mathrm{mL}$ ), interleukin (IL)-3 (10 ng/mL), stem cell factor (SCF; $50 \mathrm{ng} / \mathrm{mL}$ ), or a combination of five cytokines (erythropoietin $2 \mathrm{U} / \mathrm{mL}, \mathrm{G}-\mathrm{CSF}, \mathrm{SCF}, \mathrm{IL}-3$, and GM-CSF). Colony-forming units in culture (CFU-Cs) were scored 7 to 10 days later. Bars represent the mean number of CFU-Cs \pm standard deviation (SD) at various doses and in the presence of different cytokines. ${ }^{*} p<0.05$ compared with WT; $* * p<0.05$ compared with WT. (B) $1.5 \times 10^{4}$ LDBM cells were grown in methyl-cellulose in the presence of indicated concentrations of G-CSF, GM-CSF, and M-CSF. CFU-Cs were scored 7 to 10 days later. Bars represent the mean number of CFU-Cs $\pm \mathrm{SD}$ at the indicated doses in the presence of different cytokines. $* p<0.05$ compared to WT. 
A

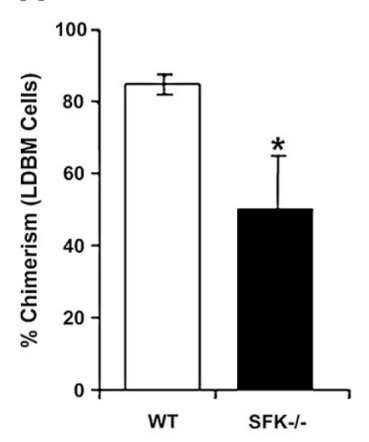

B

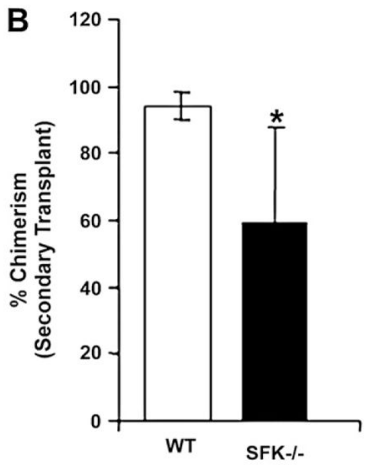

C

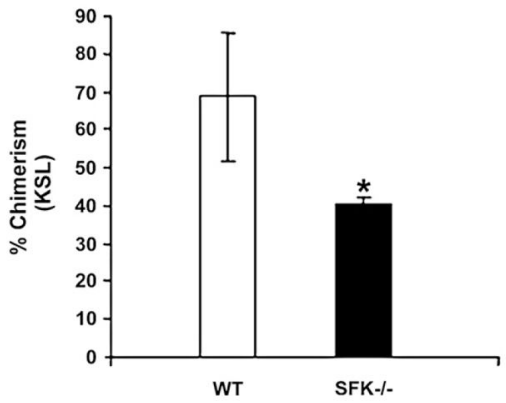

Figure 3.

Deficiency of Src family kinase (SFK) results in impaired repopulating capacity in a competitive repopulation assay. Peripheral blood chimerism in mice transplanted with wildtype (WT) or $\mathrm{SFK}^{-/-}$low-density bone marrow $(\mathrm{LDBM})(\mathbf{A})$ or $\mathrm{KIT}^{+} \mathrm{Lin}^{-} \mathrm{Sca}-1^{+}$cells $(\mathbf{C})$ and $1 \times 10^{5}$ competitor cells. Mean chimerism for LDBM (A) and c-Kit ${ }^{+} \mathrm{Lin}^{-} \mathrm{Sca}-1^{+}(\mathbf{C})$ cell number transplanted was calculated for each genotype, and the data generated at 6 months after transplantation are summarized in bar graphs. Eight mice (four per genotype) were transplanted at each test cell concentration (three different concentrations were used: 1:1, 1:2, and 1:3 for LDBM cells and two different concentrations were used for $\mathrm{Kit}^{+} \mathrm{Lin}^{-} \mathrm{Sca}-{ }^{+}$ cells (1000 and 10,000). Experiments using LDBM were repeated twice. A total of 32 mice were transplanted (16 per genotype). Shown are data from 1:1 ratio in LDBM and 10,000 $\mathrm{KIT}^{+}$Lin-Sca- ${ }^{+}$cells. Mean \pm standard deviation (SD), $* p<0.05 \mathrm{SFK}^{-/-}$vs WT. (B) LDBM cells from lethally irradiated primary recipients transplanted with WT or $\mathrm{SFK}^{-/-} \mathrm{BM}$ that demonstrated the highest chimerism (1:3; competitor-to-test ratio) were harvested and 1 $\times 10^{6}$ cells were transplanted into lethally irradiated secondary hosts. Mean chimerism was calculated for each genotype and data generated at 6 months after secondary transplantation are summarized in bar graphs. BM from 2 independent $\mathrm{WT}$ and $\mathrm{SFK}^{-/-}$primary recipients were transplanted into 24 lethally irradiated (12 for each genotype) mice. Mean $\pm \mathrm{SD},{ }^{*} p<$ $0.05, \mathrm{SFK}^{-1-}$ vs WT. KSL $=\mathrm{KIT}^{+} \mathrm{Sca}^{-1}{ }^{+} \mathrm{Lin}^{-}$. 

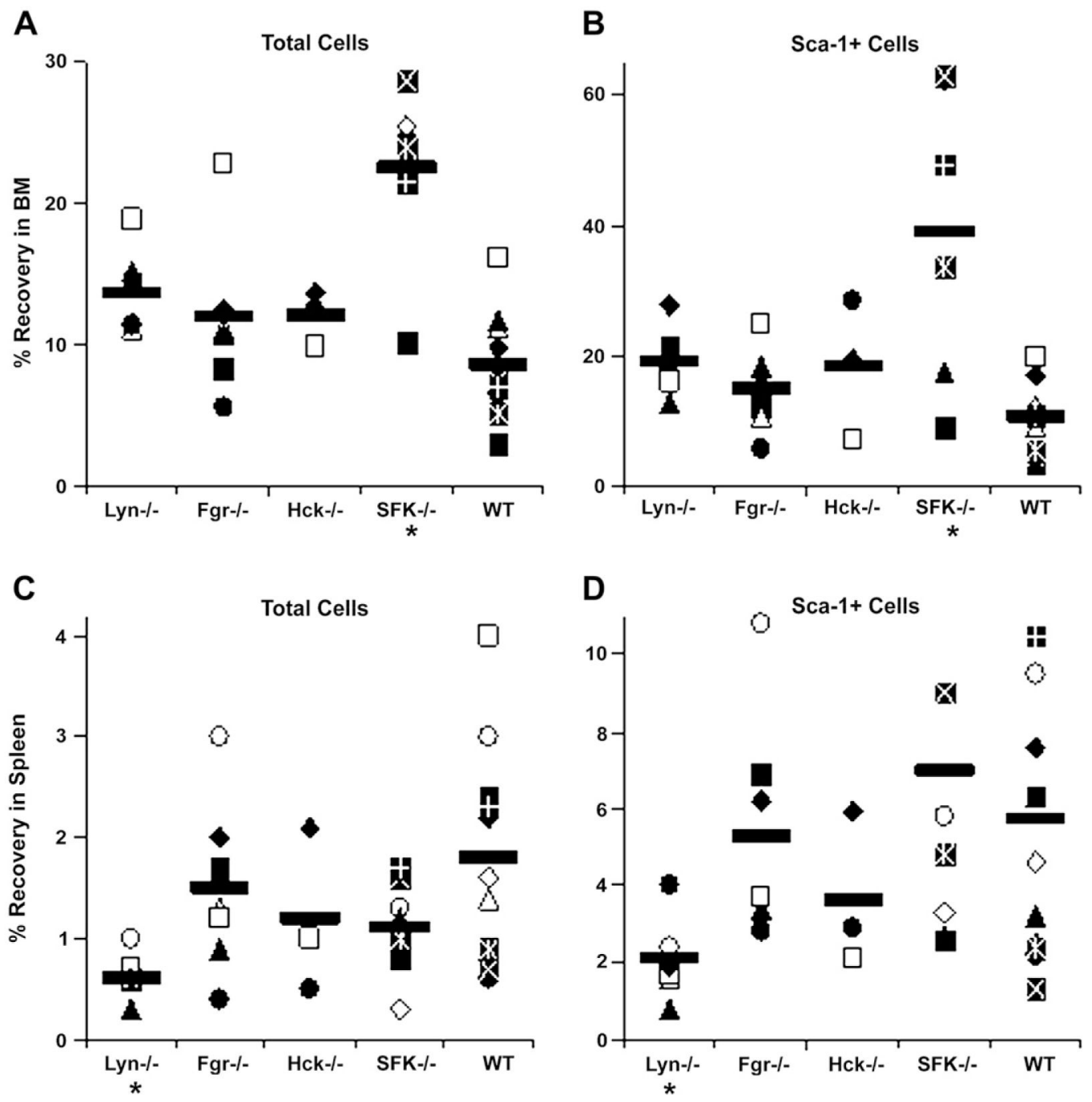

Figure 4.

Percent recovery of transplanted Src family kinases (SFK) knockout cells in bone marrow (BM) and spleen. Irradiated wild-type (WT) mice received $17.5 \times 10^{6}$ to $20 \times 10^{6}$ lowdensity BM cells isolated from $\mathrm{Lyn}^{-/}, \mathrm{Fgr}^{-/}, \mathrm{Hck}^{-/}, \mathrm{SFK}^{--}$, or WT mice, sacrificed 16 to 19 hours later, and percent recovery of total donor cells and donor Sca- $1^{+}$cells in harvested $\mathrm{BM}(\mathbf{A}, \mathbf{B})$ and spleen $(\mathbf{C}, \mathbf{D})$ were calculated as described in Materials and Methods. Data represent percent recovery in individual mice in 3 to 11 separate experiments; mean is given by horizontal line. ${ }^{*} p<0.05$ compared with WT. 
A

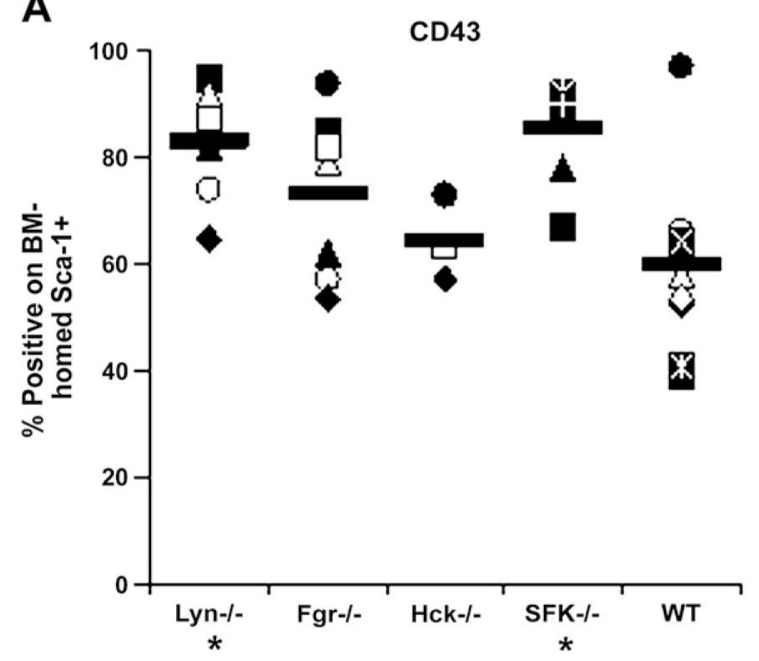

C

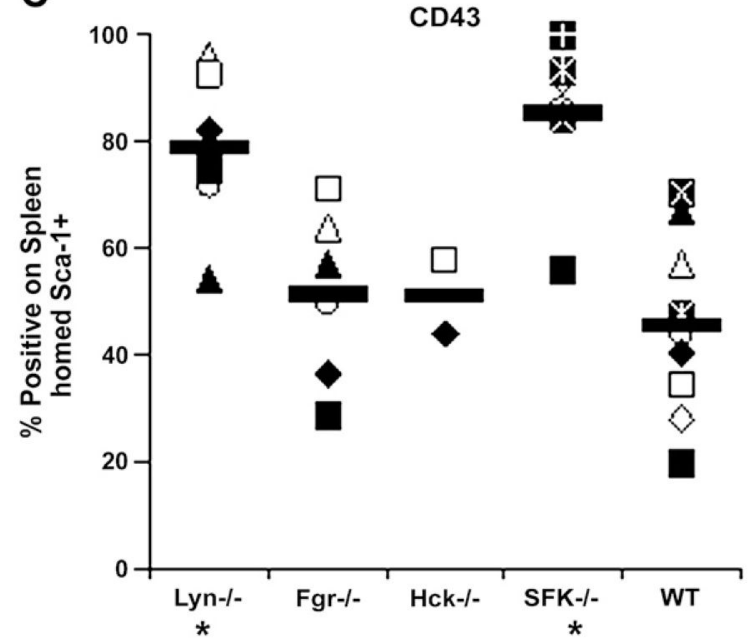

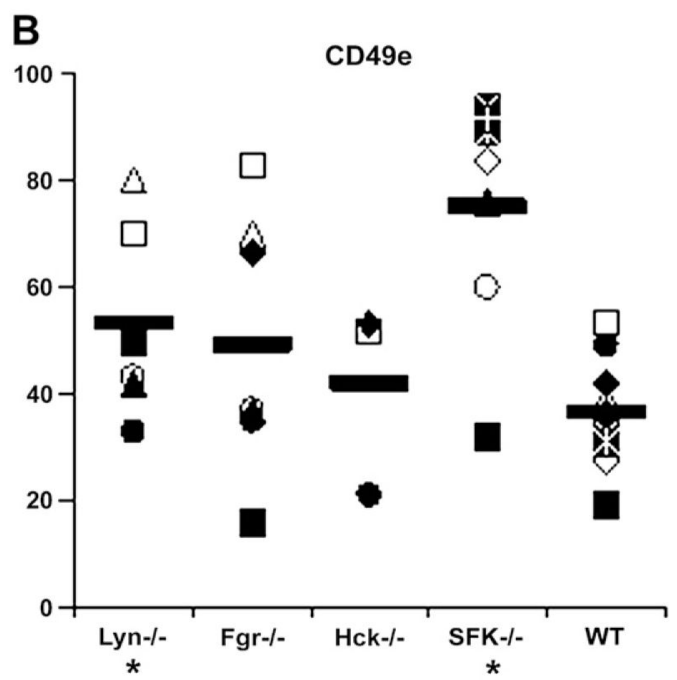

D

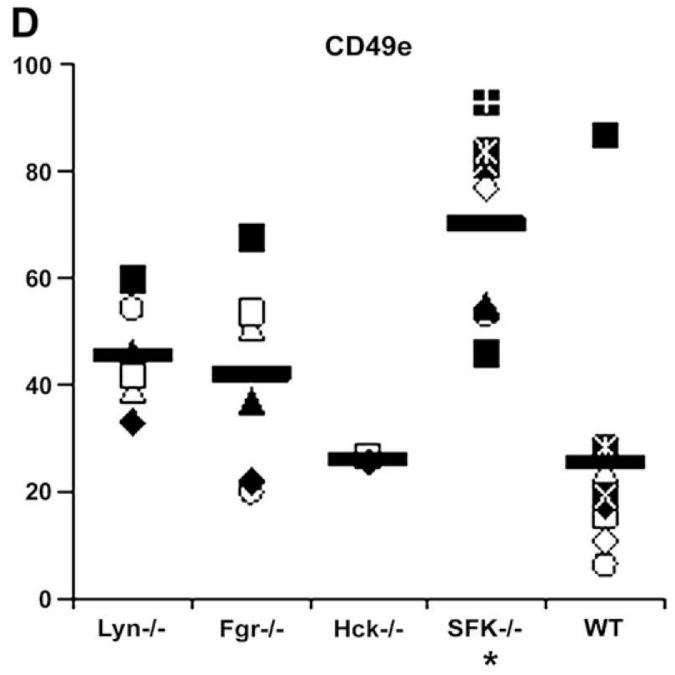

Figure 5.

Frequency of $\mathrm{CD}_{4} 3^{+}$and $\mathrm{CD} 49 \mathrm{e}^{+}$cells among donor Sca- $1^{+}$cells homed to bone marrow (BM) or spleen after transplantation. Irradiated wild-type (WT) mice received $17.5 \times 10^{6}$ to $20 \times 10^{6}$ low-density LDBM cells isolated from $\mathrm{Lyn}^{-/}, \mathrm{Fgr}^{-/}, \mathrm{Hck}^{-/}$, Src family kinases $(\mathrm{SFK})^{-/-}$, or wild-type (WT) mice, sacrificed 16 to 19 hours later, and expression of CD43 and CD49e examined on donor Sca- $1^{+}$cells recovered in BM $(\mathbf{A}, \mathbf{B})$ and spleen $(\mathbf{C}, \mathbf{D})$. Data represent percentage of recovered donor Sca- $1^{+}$cells expressing CD43 or CD49e in individual mice in four to nine separate experiments; mean is given by horizontal line. ${ }^{*} p<$ 0.05 compared with WT. 

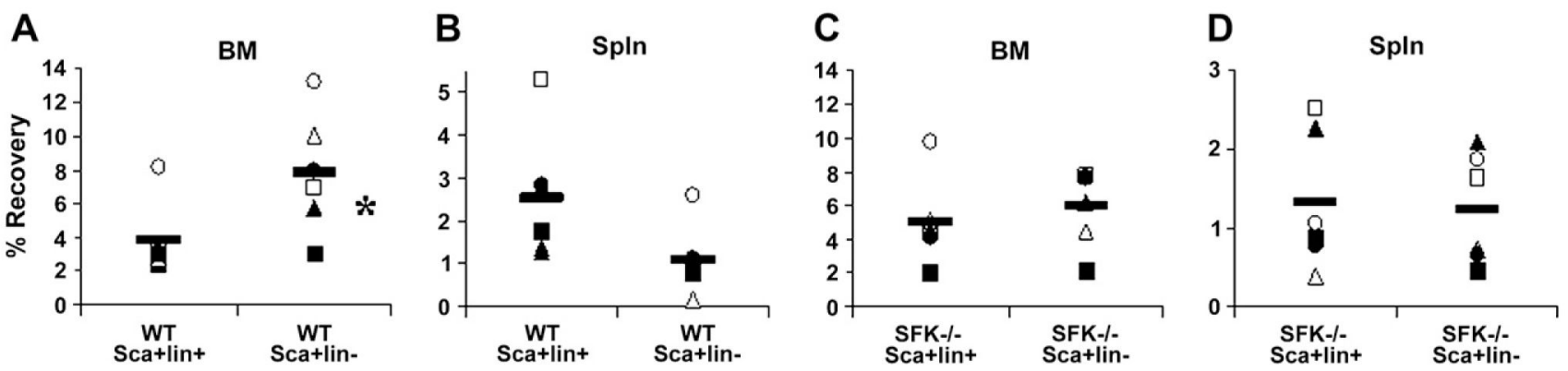

Figure 6.

Percent recovery of transplanted Src family kinase $(\mathrm{SFK})^{-/-}$or wild-type (WT) Sca- $1^{+}$lin $^{+}$ or Sca- $1^{+}$lin $^{-}$graft cells in bone marrow (BM) and spleen of WT recipients. Irradiated WT mice received $1.4 \times 10^{5}$ to $1.6010^{5}$ purified Sca- $1^{+} \operatorname{lin}^{+}$or Sca- $1^{+} \operatorname{lin}^{-}$cells isolated from $\mathrm{SFK}^{-/-}$or WT mice, sacrificed 16 to 19 hours later, and percent recovery of total donor cells in harvested BM $(\mathbf{A}, \mathbf{C})$ and spleen $(\mathbf{B}, \mathbf{D})$ was calculated as described in Materials and Methods. Data represent \% recovery in individual mice in four separate experiments $(\mathrm{n}=6$ mice total); horizontal line represents mean. ${ }^{*} p<0.05$ compared with WT. 


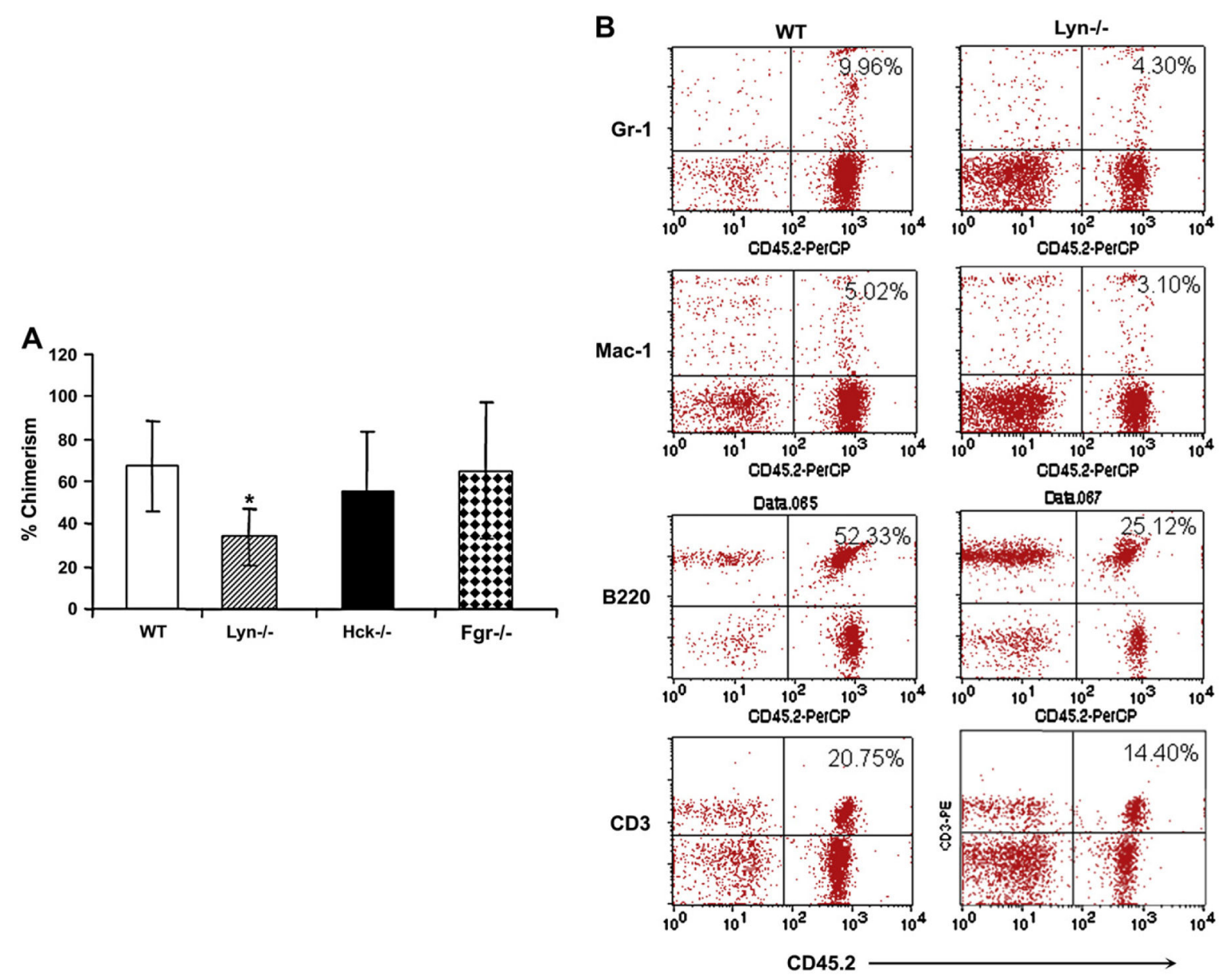

Figure 7.

Competitive repopulating ability of hematopoietic stem/progenitor (HSC/P) cells lacking expression of Hck, Fgr, or Lyn. (A) Peripheral blood (PB) lineage chimerism in mice transplanted with wild-type (WT), $\mathrm{Hck}^{-/}, \mathrm{Lyn}^{-/-}$, or $\mathrm{Fgr}^{-/-}$low-density bone marrow (BM) cells and $1 \times 10^{5}$ competitor cells. Mean chimerism for each genotype was calculated and the data generated at 4 months after transplantation are summarized in bar graphs.

Experiments were repeated twice with four to five mice in each group. Shown are data from

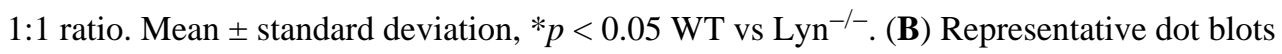
indicating multilineage engraftment of WT and $\mathrm{Lyn}^{-/-}$stem cells into myeloid and lymphoid lineages. PB cells were stained with antibodies that recognize myeloid and lymphoid lineages. Shown are percentages of donor cells from a representative mouse engrafted with WT or $\mathrm{Lyn}^{-/-}$BM cells and competitors. 

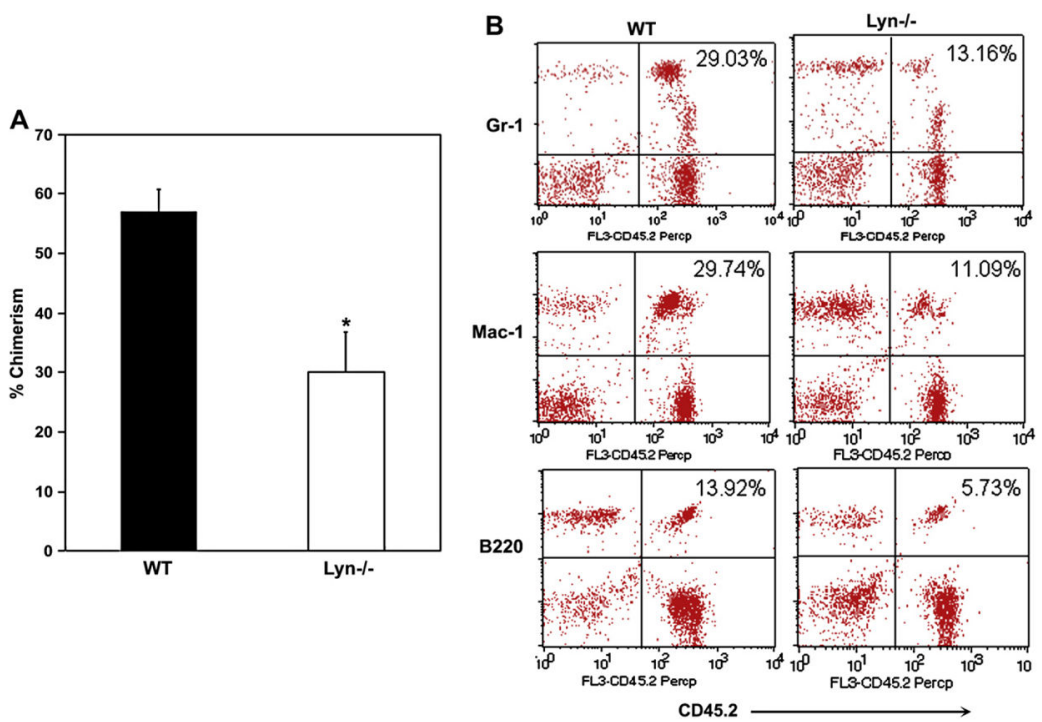

Figure 8.

Reduced engraftment of $\mathrm{Lyn}^{-/}$stem cells in lethally irradiated secondary recipients. Bone marrow (BM) of wild-type (WT) or $\mathrm{Lyn}^{-/-}$primary recipients were harvested after 4 months of primary transplantation and $1 \times 10^{6}$ low-density BM (LDBM) cells were transplanted into lethally irradiated secondary hosts. (A) Shows the mean chimerism for each genotype after 12 weeks post secondary transplantation. LDBM cells from a WT and $\mathrm{Lyn}^{-/}$primary recipient were transplanted into four to five lethally irradiated secondary recipients. Mean \pm SD, $* p<0.05$, Lyn $^{-/-}$vs WT. (B) Representative dot blots indicating myeloid and lymphoid lineage engraftment in secondary recipients. Shown are percentages of donor cells from a representative mouse engrafted with WT or $\mathrm{Lyn}^{-/-}$LDBM cells. 